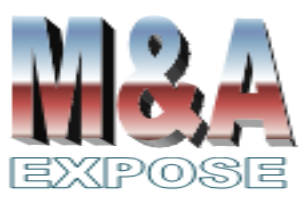

http://jurnal.usahid.ac.id/index .php/accounting
${ }^{1}$ Fakultas Ekonomi dan Bisnis Universitas Sahid madevinava@gmail.com

${ }^{2}$ Fakultas Ekonomi dan Bisnis Universitas Sahid

${ }^{3}$ Fakultas Ekonomi dan Bisnis Universitas Sahid

\section{Analisis Penerapan Standar Resep dan Kualitas Makanan di Pizza Marzano Kota Kasablanka}

\author{
Ni Luh Made Vinaya ${ }^{1}$, \\ Tanjung Prasetyo ${ }^{2}$, \\ Taruna Mudha Harisyana ${ }^{3}$
}

\section{Abstrak}

Penelitian ini bertujuan menganalisis standar resep makanan, penerapan standar resep, dan kualitas makanan di restoran Pizza Marzano. Penelitian ini berdasarkan hasil pengamatan bahwa terdapat ketidakkonsistenan sajian makanan yang memunculkan terjadinya keluhan pelanggan. Metode penelitian yang digunakan adalah analisis kualitatif dengan teknik analisis reduksi data, penyajian data, penarikan kesimpulan dan trianggulasi. Penelitian dilakukan terhadap enam orang staff dapur dan dua supervisor dapur. Kesimpulan yang diperoleh adalah bahwa restoran ini memiliki format standar resep yang memuat informasi-informasi untuk mengolah makanan dengan konsistensi kualitas dan kuantitas yang baik; penerapan standar resep karyawan dapur Pizza Marzano menerapkan bahan-bahan, petunjuk pembuatan, dan petunjuk penyajian, tetapi tidak melakukan penerapan takaran ukur yang baku; dan kualitas makanan yang dihasilkan pun tidak konsisten.

Kata kunci : standar resep, penerapan standar resep, kualitas makanan.

\section{Abstract}

This study aims to analyze food recipe standards, application of recipe standards, and food quality in Pizza Marzano restaurant. This research is based on the observation that there are inconsistencies in food offerings that lead to customer complaints. The research method used is qualitative analysis with data reduction analysis techniques, data presentation, drawing conclusions and triangulation. The study was conducted on six kitchen staff and two kitchen supervisors. The conclusion obtained is that this restaurant has a standard recipe format that contains information for processing food with good quality and quantity consistency; application of Pizza Marzano's kitchen employee recipe standard applies ingredients, manufacturing instructions, and presentation instructions, but does not apply standard measuring measures; and the quality of food produced is not consistent.

Keywords: recipe standards, application of recipe standards, food quality. 
Analisis Penerapan Standar Resep dan Kualitas Makanan....

Ni Luh Made Vinaya, Tanjung Prasetyo, Taruna Mudha Harisyana

\section{PENDAHULUAN}

Pariwisata saat ini telah berkembang pesat menjadi industri besar sebagaimana tercantum pada perhitungan devisa di tahun 2017, pariwisata termasuk lima besar devisa terhadap sebelas ekspor barang terbesar lainnya (kemenpar.go.id, 2018). Jakarta sebagai Ibu Kota Negara menjadi salah satu destinasi utama wisatawan. Banyaknya wisatawan yang datang ke Jakarta membuat bermunculannya bisnis-bisnis baru untuk memenuhi kebutuhan para wisatawan, seperti akomodasi dan konsumsi. Saat ini di Jakarta telah tersedia 332 hotel berbintang, 3.173 restoran, dan 40 balai pertemuan (jakarta.go.id). berdasarkan fenomena tersebut, restoran menjadi salah satu bisnis yang diminati untuk memenuhi kebutuhan wisatawan. Wisatawan yang berkunjung ke Jakarta merupakan wisatawan nusantara maupun wisatawan mancanegara dengan selera makan tradisional dan internasional.

Menurut data Badan Pusat Statistik, restoran makanan asing yang popular adalah masakan Amerika dan Eropa, salah satunya masakan Itali khususnya pizza. Kepopuleran menu makanan pizza membuat restoran pizza bukan hanya digemari oleh orang asing tetapi juga digemari oleh orang Indonesia. Munculnya banyak restoran pizza di Jakarta, mulai dari yang menyediakan pizza otentik Itali sampai dengan pizza yang telah disesuaikan dengan lidah orang Indonesia. Salah satu restoran pizza yang ada di Jakarta adalah Pizza Marzano. Menurut situs zomato.com, Pizza Marzano mendapat rating 4,0 atau posisi 5 besar di antara restoran pizza lain di Jakarta berdasarkan harga dan kualitas makanan serta suasana dan pelayanan. Selain melihat rating, pengamatan langsung di restoran menghasilkan beberapa kekurangan yang mengarah pada keluhan pengunjung seperti ketidakkonsistenan pada sajian makanan terutama topping pada pizza (kualitas makanan), waktu menunggu yang cukup lama, dan kontaminasi makanan. Peneliti menduga bahwa tidak diterapkannya standar resep dengan baik akan berdampak pada kualitas makanan yang komplain. Oleh karena itu perlu dilakukan penelitian lanjut mengenai penerapan standar resep dan pengukuran kualitas makanan demi kebaikan manajemen restoran.

\section{TINJAUAN PUSTAKA}

Bauran pemasaran dinayatakan Kotler \& Keller (2013) sebagai seperangkat alat pemasaran yang meliputi product (produk), price (harga), place (tempat atau saluran distribusi), dan promotion (promosi), atau dikenal dengan 4P. Adapun pemasaran jasa memiliki beberapa pemasaran tambahan seperti people (orang), physical evidence (fasilitas fisik), dan process (proses), sehingga dikenal dengan istilah 7P. Produk menjadi fokus pada bauran pemasaran. Produk menurut Kotler \& Armstrong (2018) adalah apa yang dapat ditawarkan didalam pasar untuk dipertahankan, dimiliki, digunakan atau dikonsumsi sehingga dapat memuaskan keinginan atau kebutuhan, termasuk objek fisik, jasa, orang, tempat organisasi dan gagasan.

Tjiptono (2012) menyatakan kualitas sebagai kondisi dinamis yang berhubungan dengan produk, jasa, sumber daya manusia, proses, dan lingkungan yang memenuhi atau melebihi harapan. Berkaitan dengan konsep kualitas, Tjiptono (2012) melakukan evaluasi terhadap banyaknya definisi konsep kualitas, kemudian menarik kesimpulan tentang tujuh definisi yang paling sering dikemukakan tentang konsep kualitas, yaitu : (1) kesesuaian 
dengan persyaratan dan tuntutan, (2) kecocokan untuk pemakaian, (3) perbaikan atau penyempurnaan yang berkelanjutan, (4) bebas dari kerusakan atau cacat, (5) pemenuhan kebutuhan pelanggan semenjak awal dan setiap saat, (6) melakukan sesuatu secara benar semenjak awal, dan (7) sesuatu yang membahagiakan pelanggan.

Garvin dalam Tjiptono (2012) menemukan setidaknya ada lima perspektif kualitas yang berkembang saat ini, yaitu (1) transcendental approach, (2) product-based approach, (3) user-based approach, (4) manufacturing-based approach, dan (5) value-based approach. Pada penelitian ini, product-based approach atau pendekatan kualitas berdasarkan produk di mana perspektif ini mengasumsikan bahwa kualitas merupakan karakteristik, komponen atau atribut objektif yang dapat dikuantitatifkan dan dapat diukur. Perbedaan dalam hal kualitas mencerminkan perbedaan dalam jumlah beberapa unsur atau atribut yang dimiliki produk. Semakin banyak atribut yang dimiliki sebuah produk atau merek, semakin berkualitas produk atau merek bersangkutan.

Produk pada penelitian adalah produk makanan yaitu pizza. Pengertian makanan menurut Sudira dalam Novayanti \& Sholikin (2016) adalah suatu kebutuhan langsung berhubungan dengan kehidupan manusia dan bila dimakan atau masuk ke dalam perut maka akan sulit dikeluarkan kembali. Sedangkan menurut Alwi yang dikutip oleh Novayanti \& Sholikin (2016) makanan adalah segala bahan yang kita makan atau masuk kedalam tubuh membentuk atau mengganti semua metabolisme tubuh. Ceserani et all (2007) menyatakan bahwa kualitas produk makanan di dapur dapat dicapai dengan: (1) kualitas bahan makanan, (2) keterampilan juru masak, (3) kelengkapan peralatan dapur, dan (4) penggunaan standar resep makanan. Untuk itu, setiap produk makanan memiliki suatu standar resep.

Standar resep makanan menurut Jhon dalam Mufqi (2016) adalah intruksi tertulis untuk menghasilkan suatu produk makanan yang di dalamnya terdapat informasi tentang kebutuhan bahan, banyaknya kebutuhan bahan, prosedur persiapan, ukuran porsi, alat-alat yang dibutuhkan, garnish, dan informasi lain yang dibutuhkan untuk menyiapkan bahan atau alat. Standar resep makanan juga memberikan informasi tentang cara memasaknya, oleh karena itu juru masak harus dapat mengerti isi dari standar resep makan. Standar resep sangat berpengaruh dalam memproduksi makan yang berkualitas dan dapat di jadikan acuan dalam proses produksi, maka kelengkapan informasi standart resep harus diutamakn dan ditetapkan seperti yang dilampirkan oleh United State of Departemen Agiculture (USDA) dalam Mufqi (2016) bahwa standar resep harus berisi bahan-bahan yang diperlukan: (1) name of recipe (nama resep masakan), (2) ingredient list (bahan-bahan yang diperlukan), (3) weight and measure (takaran ukuran), (4) preparation direction (petunjuk persiapan), (5) serving direction (petunjuk penyajian), (6) yield (jumlah porsi), (7) portion size information (ukuran porsi), (8) variation (variasi), (9) nutrient per-serving (nutrisi per porsi), dan (10) equipment needed (kebutuhan peralatan). Standar resep memiliki struktur, menurut Nurzinah dalam Tri (2014) yaitu: (1) nama resep, (2) hasil, termasuk porsi dan ukuran, (3) bahan makanan dan jumlah, (4) alat yang di butuhkan, (5) petunjuk dalam persiapan dan pemasak, (6) waktu yang dibutuhkan untuk persiapan dan memasak, (7) cara menghidangkan (porsi, alat, garnis), dan (8) petunjuk untuk penyimpanan. Setelah makanan dimasak dan disajikan maka langkah selanjutnya adalah penilaian kualitas makanan tersebut.

Margaretha \& Japrianto (2012) menyatakan bahwa secara garis besar faktor-faktor yang mempengaruhi food quality meliputi : (1) warna, (2) penampilan, (3) porsi, (4) bentuk, 
(5) temperatur, (6) tekstur, (7) aroma, (8) tingkat kematangan, dan (9) rasa. Pendapat lain menurut Marsum (2005), hal-hal yang harus diterapkan dalam kualitas makanan, antara lain: (1) flavor/rasa, (2) consistency/ketetapan, (3) texture, form, shape/tektur, bentuk, potongan, (4) nutritional content/kandungan gizi, (5) visual appeal/daya tarik lewat ketajaman mata, (6) aromatic appeal/daya tarik lewat aroma, dan (7) temperature/suhu.

Adapun Wijaya (2017) mengemukakan bahwa quality of food (kualitas makanan) dan quality of service (kualitas layanan) merupakan atribut-atribut utama yang mempengaruhi kepuasan konsumen. Kualitas makanan secara umum sudah diterima sebagai salah satu elemen yang mendasar dari keseluruhan pengalaman konsumen di restoran. Kualitas makanan menurut Alli (2009) dalam Wijaya (2017) adalah semua ketentuan yang telah ditetapkan berhubungan dengan karakteristik kualitas makanan yang diperlukan untuk memuaskan keinginan dan harapan konsumen. Selanjutnya, Qin et al. (2009) dalam Wijaya (2017) menyatakan kualitas produk pada bidang food and beverage memiliki empat dimensi, yaitu (1) freshness (kesegaran makanan), (2) presentation (penyajian makanan), (3) well cooked (makanan yang dimasak dengan baik/tepat), dan (4) variety of food (keanekaragaman makanan). Apabila kualitas makanan yang diberikan bagus akan menguntungkan kedua belah pihak, bagi pihak restoran akan mendapatkan citra yang baik dan keuntungan dalam bisnisnya, sedangkan bagi pelanggan akan mendapatkan kepuasan yang diharapkan. Penelitian Namkung dan Jang (2007) dalam Wijaya (2017) menerangkan bahwa kualitas makanan adalah salah satu cara terbaik untuk memaksimalkan keberhasilan dalam bisnis restoran. Pendapat tersebut diperkuat kembali oleh Ryu dan Han (2010), kualitas makanan adalah atribut yang paling penting dari keseluruhan kualitas layanan dan memiliki hubungan positif dengan kepuasan dan loyalitas pelanggan, walau memang dalam penelitian ini belum jauh meneliti hingga kepuasan dan loyalitas konsumen.

\section{METODE PENELITIAN}

Metode penelitian yang digunakan dalam kesempatan penelitian ini dilakukan pendekatan secara kualitatif, karena bersifat deskriptif dan cenderung menggunakan analisis yang bersumber dari data dan memanfaatkan teori yang ada sebagai bahan penjelas (Anggito, 2008). Sumber data berupa data primer diperoleh langsung dari staf dan supervisor dapur mengenai penerapan standar resep makanan dan kualitas makanan. Data sekunder yang berupa data rangking devisa pariwisata tahun 2017, perkembangan jumlah wisatawan ke Jakarta, pertumbuhan restoran di Jakarta, persentase banyaknya usaha restoran berskala menengah menurut jenis makanan, dan rating data restoran pizza terbaik di Jakarta didapat secara eksternal dari berbagai situs terpercaya seperti Badan Pusat Statistik dan zomato.com.

Pengumpulan data dilakukan langsung di lapangan dengan memberikan kuesioner dengan daftar pertanyaan terbuka sesuai dengan variabel. Selain dengan kuesioner, pegumpulan data juga dilakukan melalui wawancara. Responden penelitian ini berjumlah delapan orang yang terdiri dari enam staf dapur, satu kepala dapur, dan satu asisten kepala dapur. Selanjutnya, analisis data dilanjutkan dengan reduksi data di mana data observasi, wawancara, dan kuesioner direduksi dengan cara merangkum, memilih hal-hal yang pokok dan penting, mengklasifikasikan sesuai rumusan masalah dalam penelitian ini sehingga mempermudah analisis dan pengambilan kesimpulan. Secara keseluruhan, penelitian ini menggunakan metode triangulasi yang merupakan pendekatan multimetode yang dilakukan 
peneliti pada saat mengumpulkan dan menganalisis data. Peneliti membandingkan jawaban kuesioner dengan standar Pizza Marzano, kemudian juga membandingkan dengan teori dan studi kepustakaan mengenai standar resep dan kualitas makanan. Melalui metode tersebut, pengecekan kebenaran data atau informasi yang diperoleh peneliti dari berbagai sudut pandang yang berbeda menjadi akurat, karena mengurangi sebanyak mungkin bias yang terjadi pada saat pengumpulan dan analisis data.

\section{HASIL DAN PEMBAHASAN}

Hasil penelitian dijabarkan dalam tabel berikut yang berisi tentang standar resep, penerapan standar resep, dan kualitas makanan. Berikut pembahasan masing-masing tabel tersebut.

Tabel 1. Analisis Standar Resep Pizza Marzano menurut United State of Departemen Agiculture (USDA)

\begin{tabular}{|c|c|c|c|c|c|}
\hline No & Dimensi & Indikator & Sesuai & $\begin{array}{l}\text { Tidak } \\
\text { Sesuai }\end{array}$ & Analisa \\
\hline & & $\begin{array}{l}\text { Nama Resep } \\
\text { makanan }\end{array}$ & $\sqrt{ }$ & & \multirow{3}{*}{$\begin{array}{l}\text { Terdapat nama resep makanan } \\
\text { di pojok kanan atas how to card, } \\
\text { tetapi tidak dijelaskan makna } \\
\text { dari nama makanan yang } \\
\text { mengandung arti dari bahan- } \\
\text { bahan yang digunakan dan cara } \\
\text { pengolahan }\end{array}$} \\
\hline & Nama & & & & \\
\hline 1 & $\begin{array}{l}\text { Resep } \\
\text { Makanan }\end{array}$ & $\begin{array}{l}\text { Pengertian nama } \\
\text { resep makanan }\end{array}$ & & $\sqrt{ }$ & \\
\hline 2 & $\begin{array}{l}\text { Bahan- } \\
\text { bahan } \\
\text { yang di } \\
\text { perlukan }\end{array}$ & $\begin{array}{l}\text { Nama bahan } \\
\text { makanan, bumbu, dan } \\
\text { rempah yang } \\
\text { digunakan }\end{array}$ & $\sqrt{ }$ & & $\begin{array}{l}\text { Dalam kotak you will need pada } \\
\text { how to card terdapat nama } \\
\text { nama bahan makanan yang } \\
\text { digunakan termasuk bumbu dan } \\
\text { rempah yang akan digunakan }\end{array}$ \\
\hline 3 & $\begin{array}{l}\text { Takaran } \\
\text { ukuran }\end{array}$ & $\begin{array}{l}\text { Takaran dari bahan } \\
\text { yang digunakan }\end{array}$ & $\sqrt{ }$ & & $\begin{array}{l}\text { Terdapat takaran dikotak you } \\
\text { will need dari bahan-bahan yang } \\
\text { digunakan dengan } \\
\text { menggunakan satuan ukuran } \\
\text { seperti, gram, } m l, p c s, \text { pinch, } \\
\text { dan lain-lain. }\end{array}$ \\
\hline \multirow{3}{*}{4} & Petunjuk & $\begin{array}{l}\text { Petunjuk persiapan } \\
\text { potongan bahan } \\
\text { makanan } \\
\end{array}$ & & $\sqrt{ }$ & \multirow{3}{*}{$\begin{array}{l}\text { Terdapat langkah langkah } \\
\text { pembuatan di how to card, } \\
\text { dilengkapi dengan gambar dari } \\
\text { langkah-langkah pembuatan } \\
\text { tetapi } \\
\text { tidak ada petunjuk pemotongan } \\
\text { bahan makanan. }\end{array}$} \\
\hline & $\begin{array}{l}\text { Pembuat } \\
\text { an }\end{array}$ & $\begin{array}{l}\text { Langkah langkah } \\
\text { pembuatan }\end{array}$ & $\sqrt{ }$ & & \\
\hline & & $\begin{array}{l}\text { Gambar dari langkah } \\
\text { langkah pembuatan }\end{array}$ & $\sqrt{ }$ & & \\
\hline \multirow[t]{2}{*}{5} & \multirow{2}{*}{$\begin{array}{l}\text { Petunjuk } \\
\text { Penyajian }\end{array}$} & $\begin{array}{l}\text { Langkah langkah } \\
\text { penyajian }\end{array}$ & $\sqrt{ }$ & & $\begin{array}{l}\text { Terdapat penjelasan mengenai } \\
\text { langkahlangkah penyajian dan } \\
\text { urutan peletakan }\end{array}$ \\
\hline & & Garnish & $\sqrt{ }$ & & $\begin{array}{l}\text { Terdapat garnish untuk } \\
\text { memperindah makanan }\end{array}$ \\
\hline
\end{tabular}


Analisis Penerapan Standar Resep dan Kualitas Makanan....

Ni Luh Made Vinaya, Tanjung Prasetyo, Taruna Mudha Harisyana

\begin{tabular}{|c|c|c|c|c|c|}
\hline No & Dimensi & Indikator & Sesuai & $\begin{array}{l}\text { Tidak } \\
\text { Sesuai }\end{array}$ & Analisa \\
\hline & & $\begin{array}{l}\text { Susunan peletakan } \\
\text { makanan di piring }\end{array}$ & $\sqrt{ }$ & & $\begin{array}{l}\text { Terdapat gambar pelatakan } \\
\text { makanan di piring }\end{array}$ \\
\hline \multirow{2}{*}{6} & \multirow{2}{*}{ Porsi } & Ukuran porsi makanan & & $\sqrt{ }$ & \\
\hline & & Jumlah porsi makanan & & $\sqrt{ }$ & \\
\hline \multirow[t]{2}{*}{8} & \multirow[t]{2}{*}{ Nutisi } & $\begin{array}{l}\text { Kandungan nutrisi } \\
\text { yang ada dimakanan } \\
\text { seperti kalori, lemak, } \\
\text { vitamin, dll }\end{array}$ & & $\sqrt{ }$ & $\begin{array}{l}\text { Tidak terdapat jumlah } \\
\text { kandungan nutrisi }\end{array}$ \\
\hline & & $\begin{array}{l}\text { Kandungan bahan } \\
\text { makanan penyebab } \\
\text { alaergi dan makanan }\end{array}$ & $\sqrt{ }$ & & $\begin{array}{l}\text { Terdapat kandu } \sqrt{\text { ngan bahan }} \\
\text { penyebab alergi dan makanan } \\
\text { vegetarian }\end{array}$ \\
\hline \multirow{2}{*}{9} & Peralatan & $\begin{array}{l}\text { Peralatan yang } \\
\text { dibutuhkan }\end{array}$ & & $\sqrt{ }$ & \\
\hline & Memasak & $\begin{array}{l}\text { Gambar peralatan } \\
\text { makanan }\end{array}$ & & $\sqrt{ }$ & \\
\hline
\end{tabular}

Penelitian tentang standar resep di Pizza Marzano ini dilakukan dengan melampirkan format standar resep makanan atau yang biasa disebut How to card yang dimiliki oleh Pizza Marzano yang merupakan petunjuk dalam membuat suatu produk makanan dengan kualitas dan kuantitas yang konsisten. Peneliti menganalisis petunjuk pada How to card dengan standar resep menurut Unites State of Departement Agriculture (USDA) seperti dalam Mufqi (2015). Hasil pada Tabel 1 Analisis Standar Resep Pizza Marzano menurut United State of Departemen Agiculture (USDA) adalah lebih banyak petunjuk How to card yang sesuai dengan standar resep USDA. Selanjutnya peneliti menanyakan tentang penerapan standar resep yang sudah ada kepada 6 orang staff dapur. Hasilnya dapat dilihat pada Tabel Analisis Penerapan Standar Resep oleh Staff Dapur di Pizza Marzano.

Tabel 2. Penerapan Standar Resep oleh Staff Dapur Pizza Marzano

\begin{tabular}{|c|c|c|c|c|c|c|c|c|c|}
\hline No & Dimensi & Indikator & $A$ & $B$ & $\mathrm{C}$ & $D$ & $E$ & $F$ & Analisis \\
\hline \multirow[b]{2}{*}{1} & \multirow{2}{*}{$\begin{array}{l}\text { Nama } \\
\text { Resep } \\
\text { Makanan }\end{array}$} & $\begin{array}{l}\text { Nama Resep } \\
\text { makanan }\end{array}$ & $\sqrt{ }$ & $\sqrt{ }$ & $\sqrt{ }$ & $\sqrt{ }$ & $\sqrt{ }$ & $\sqrt{ }$ & \multirow{2}{*}{$\begin{array}{l}\text { Karyawan } \\
\text { mengetahui nama } \\
\text { resep makanan dan } \\
\text { memahami } \\
\text { pengertian resep } \\
\text { makanan. }\end{array}$} \\
\hline & & $\begin{array}{l}\text { Pengertian } \\
\text { nama resep } \\
\text { makanan }\end{array}$ & $\sqrt{ }$ & $\sqrt{ }$ & $\sqrt{ }$ & $\sqrt{ }$ & $\sqrt{ }$ & $\sqrt{ }$ & \\
\hline 2 & $\begin{array}{l}\text { Bahan- } \\
\text { bahan yang } \\
\text { di perlukan }\end{array}$ & $\begin{array}{l}\text { Nama bahan } \\
\text { makanan, } \\
\text { bumbu, dan } \\
\text { rempah yang } \\
\text { digunakan }\end{array}$ & $\sqrt{ }$ & $\sqrt{ }$ & $\sqrt{ }$ & $\sqrt{ }$ & $\sqrt{ }$ & $\sqrt{ }$ & $\begin{array}{l}\text { Karyawan } \\
\text { memahami bahan } \\
\text { makanan, bumbu } \\
\text { dan rempah yang } \\
\text { digunakan dalam } \\
\text { pembuatan } \\
\text { makanan. }\end{array}$ \\
\hline
\end{tabular}




\begin{tabular}{|c|c|c|c|c|c|c|c|c|c|}
\hline No & Dimensi & Indikator & $A$ & $B$ & C & $D$ & $E$ & $F$ & Analisis \\
\hline 3 & $\begin{array}{l}\text { Takaran } \\
\text { ukuran }\end{array}$ & $\begin{array}{l}\text { Takaran dari } \\
\text { bahan yang } \\
\text { digunakan }\end{array}$ & - & - & - & - & - & - & $\begin{array}{l}\text { Karyawan tidak } \\
\text { melakukan } \\
\text { penerapan pada } \\
\text { takaran sesuai } \\
\text { standar resep, } \\
\text { tidak semua } \\
\text { bahan makanan } \\
\text { diukur sesuai } \\
\text { standar resep } \\
\text { makanan. } \\
\end{array}$ \\
\hline \multirow{2}{*}{4} & \multirow{2}{*}{$\begin{array}{l}\text { Petunjuk } \\
\text { Pembuatan }\end{array}$} & $\begin{array}{l}\text { Petunjuk } \\
\text { persiapan } \\
\text { potongan } \\
\text { bahan } \\
\text { makanan } \\
\end{array}$ & $\sqrt{ }$ & $\sqrt{ }$ & $\sqrt{ }$ & $\sqrt{ }$ & $\sqrt{ }$ & $\sqrt{ }$ & \multirow{2}{*}{$\begin{array}{l}\text { Karyawan } \\
\text { melakukan } \\
\text { penerapan petunjuk } \\
\text { pembuatan } \\
\text { makanan, dan } \\
\text { mengetahui } \\
\text { langkah-langkah } \\
\text { pembuatan } \\
\text { makanan sesuai } \\
\text { standar resep. }\end{array}$} \\
\hline & & $\begin{array}{l}\text { Langkah } \\
\text { langkah } \\
\text { pembuatan }\end{array}$ & $\sqrt{ }$ & $\sqrt{ }$ & $\sqrt{ }$ & $\sqrt{ }$ & $\sqrt{ }$ & $\sqrt{ }$ & \\
\hline \multirow{3}{*}{5} & \multirow{3}{*}{$\begin{array}{l}\text { Petunjuk } \\
\text { Penyajian }\end{array}$} & $\begin{array}{l}\text { Langkah } \\
\text { langkah } \\
\text { penyajian }\end{array}$ & $\sqrt{ }$ & $\sqrt{ }$ & $\sqrt{ }$ & $\sqrt{ }$ & $\sqrt{ }$ & $\sqrt{ }$ & \multirow{3}{*}{$\begin{array}{l}\text { Karyawan } \\
\text { menerapkan } \\
\text { langkah-langkah } \\
\text { penyajian } \\
\text { makanan, } \\
\text { memahami garnish } \\
\text { yang digunakan, } \\
\text { dan memahami } \\
\text { susunan peletakan } \\
\text { makanan di piring. }\end{array}$} \\
\hline & & Garnish & $\sqrt{ }$ & $\sqrt{ }$ & $\sqrt{ }$ & $\sqrt{ }$ & $\sqrt{ }$ & $\sqrt{ }$ & \\
\hline & & $\begin{array}{l}\text { Susunan } \\
\text { peletakan } \\
\text { makanan di } \\
\text { piring }\end{array}$ & $\sqrt{ }$ & $\sqrt{ }$ & $\sqrt{ }$ & $\sqrt{ }$ & $\sqrt{ }$ & $\sqrt{ }$ & \\
\hline \multirow[b]{2}{*}{6} & \multirow[b]{2}{*}{ Porsi } & $\begin{array}{l}\text { Ukuran porsi } \\
\text { makanan }\end{array}$ & - & - & - & - & - & - & \multirow{2}{*}{$\begin{array}{l}\text { Karyawan tidak } \\
\text { menerapkan ukuran } \\
\text { porsi makanan } \\
\text { bahan makanan } \\
\text { secara konsisten, } \\
\text { namun memahami } \\
\text { jumlah porsi satu } \\
\text { buah pizza quarto } \\
\text { carne yaitu untuk } \\
12 \text { orang. }\end{array}$} \\
\hline & & $\begin{array}{l}\text { Jumlah porsi } \\
\text { makanan }\end{array}$ & $\sqrt{ }$ & $\sqrt{ }$ & $\sqrt{ }$ & $\sqrt{ }$ & $\sqrt{ }$ & $\sqrt{ }$ & \\
\hline 7 & Nutisi & $\begin{array}{l}\text { Kandungan } \\
\text { nutrisi yang } \\
\text { ada dimakanan } \\
\text { seperti kalori, } \\
\text { lemak, vitamin, } \\
\text { dll }\end{array}$ & - & - & - & - & - & - & $\begin{array}{l}\text { Karyawan tidak } \\
\text { mengetahui } \\
\text { kandungan nutrisi } \\
\text { yang ada dalam } \\
\text { pizza karena } \\
\text { kurangnya } \\
\text { informasi } \\
\text { dalam standar } \\
\text { resep. }\end{array}$ \\
\hline
\end{tabular}




\begin{tabular}{|c|c|c|c|c|c|c|c|c|c|}
\hline No & Dimensi & Indikator & $A$ & B & C & $D$ & $E$ & $F$ & Analisis \\
\hline & & $\begin{array}{l}\text { Kandungan } \\
\text { bahan } \\
\text { makanan } \\
\text { penyebab } \\
\text { alergi dan } \\
\text { makanan } \\
\text { vegetarian }\end{array}$ & $\sqrt{ }$ & $\sqrt{ }$ & $\sqrt{ }$ & $\sqrt{ }$ & $\sqrt{ }$ & $\sqrt{ }$ & $\begin{array}{l}\text { Karyawan } \\
\text { memahami } \\
\text { kandungan bahan } \\
\text { makanan penyebab } \\
\text { alergi dan makanan } \\
\text { vegetarian. }\end{array}$ \\
\hline
\end{tabular}

Sumber: data diolah peneliti (2018)

Hasil analisis atas penerapan standar resep adalah staf dapur tidak menggunakan takaran ukur dengan alasan penggunaan takaran ukur tidak efisien waktu pembuatan, sudah merasa percaya diri dengan kemampuan dan pengetahuan yang telah didapatkannya dari pengalaman kerja sebelumnya di tempat lain. Dengan demikian pada waktu kerja dan selama mengelola makanan mereka tidak menggunakan alat menimbang atau lebih memilih menggunakan insting yang belum tentu sesuai takaran ukurnya. Akibat dari kejadian tersebut terjadilah kualitas dan kuantitas yang berubah-ubah. Gregoire dan Spears dalam Mufqi (2016:9) menjelaskan adanya beberapa manfaat yang akan diperoleh jika proses pengolahan makanan dilaksanakan dengan mengikuti standar resep yang ditetapkan. Berikut merupakan kerugian yang dapat terjadi jika masalah takaran ukur ini dibiarkan tanpa ada solusi : (1) perbedaan durasi yang dibutuhkan dalam pembuatan menu makanan, (2) perbedaan jumlah kalori yang dihasilkan oleh setiap makanan, (3) penetapan biaya pada setiap makanan berbeda-beda per porsinya, (4) biaya pembelian bahan makanan yang tidak konsisten terhadap jumlah porsi, (5) persiapan bahan makanan yang tidak konsisten, (6) kualitas dan kuantitas akan berbeda-beda, (7) penampilan dan hiasan tidak terlihat sama, (8) operasional menjadi tidak efisien, (9) tidak terjaganya keuangan, terutama biaya makanan, dan (10) kepuasan pelanggan yang berbeda-beda.

Pada akhirnya, peneliti akan mengukur kualitas makanan yang dihasilkan staff dapur Pizza Marzano. Hasil masakan tidak dinilai oleh konsumen melainkan dinilai oleh Kepala Dapur (Head Chef/ HC) dan Asisten Kepala Dapur (Asisstant Head Chef/ AHC). Hasilnya seperti yang ada di Tabel Analisis Kualitas Makanan di Pizza Marzano.

Tabel 3. Analisis Kualitas Makanan di Pizza Marzano

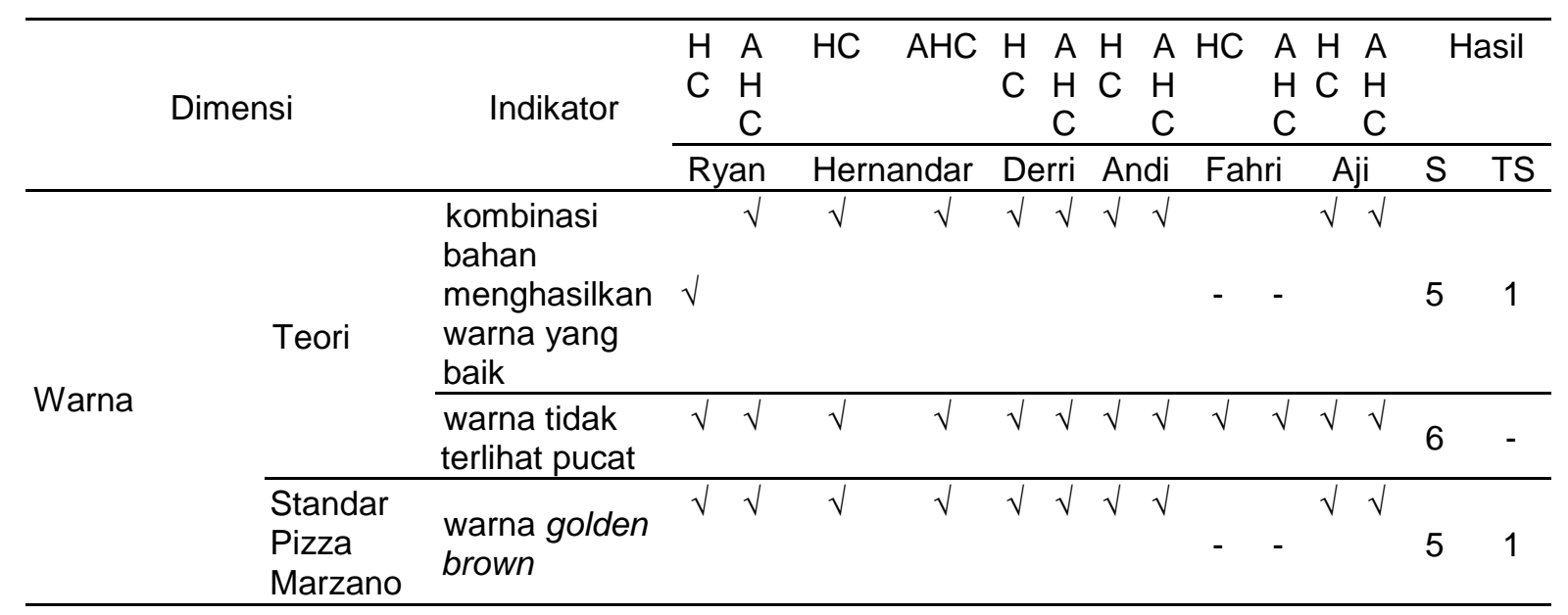




\begin{tabular}{|c|c|c|c|c|c|c|c|c|c|c|c|c|c|c|c|c|}
\hline \multicolumn{2}{|c|}{ Dimensi } & \multirow[t]{2}{*}{ Indikator } & \multirow{2}{*}{\multicolumn{2}{|c|}{$\begin{array}{ll}\mathrm{H} & \mathrm{A} \\
\mathrm{C} & \mathrm{H} \\
& \mathrm{C} \\
\text { Ryan }\end{array}$}} & \multirow{2}{*}{\multicolumn{2}{|c|}{$\begin{array}{l}\mathrm{HC} \quad \mathrm{AHC} \\
\text { Hernandar }\end{array}$}} & \multirow{2}{*}{$\begin{array}{ll}\mathrm{H} & \mathrm{A} \\
\mathrm{C} & \mathrm{H} \\
& \mathrm{C} \\
\text { Derri } \\
\end{array}$} & \multirow{2}{*}{\multicolumn{2}{|c|}{$\begin{array}{l}\mathrm{H} \\
\mathrm{C} \\
\mathrm{Ann}\end{array}$}} & \multirow{2}{*}{$\begin{array}{l}\mathrm{A} \\
\mathrm{H} \\
\mathrm{C} \\
\mathrm{di}\end{array}$} & \multirow{2}{*}{\multicolumn{2}{|c|}{$\begin{array}{rr}\mathrm{HC} & \mathrm{A} \\
& \mathrm{H} \\
\mathrm{C} \\
\text { Fahri } \\
\end{array}$}} & \multirow{2}{*}{\multicolumn{2}{|c|}{$\begin{array}{rr}\begin{array}{l}\mathrm{H} \\
\mathrm{C}\end{array} \\
\mathrm{C} \\
\mathrm{C} \\
\mathrm{Aji} \\
\end{array}$}} & \multicolumn{2}{|c|}{ Hasil } \\
\hline & & & & & & & & & & & & & & & $S$ & TS \\
\hline \multirow{5}{*}{ Penampilan } & Teori & $\begin{array}{l}\text { pengaturan } \\
\text { bahan } \\
\text { makanan }\end{array}$ & & $\sqrt{ }$ & $\sqrt{ }$ & $\sqrt{ }$ & $\begin{array}{ll}\sqrt{ } \\
\end{array}$ & & - & & . & & & v & 4 & 2 \\
\hline & & $\begin{array}{l}\text { kebersihan } \\
\text { penampilan }\end{array}$ & $\sqrt{ }$ & $\sqrt{ }$ & $\sqrt{ }$ & $\sqrt{ }$ & $\begin{array}{ll}\sqrt{ } & \sqrt{ }\end{array}$ & $\sqrt{ }$ & $\sqrt{ }$ & & $\sqrt{ }$ & $\sqrt{ }$ & $\sqrt{ }$ & $\sqrt{ }$ & 6 & - \\
\hline & $\begin{array}{l}\text { Standar } \\
\text { Pizza } \\
\text { Marzano }\end{array}$ & $\begin{array}{l}\text { topping } \\
\text { merata }\end{array}$ & $\sqrt{ }$ & $\sqrt{ }$ & $\sqrt{ }$ & $\sqrt{ }$ & $\sqrt{ } \sqrt{ }$ & & - & & . & - & $\sqrt{ }$ & $\sqrt{ }$ & 4 & 2 \\
\hline & & garnish & $\sqrt{ }$ & $\sqrt{ }$ & $\sqrt{ }$ & $\sqrt{ }$ & $\sqrt{ } \sqrt{ }$ & $\sqrt{ }$ & $\sqrt{ }$ & & $\sqrt{ }$ & $\sqrt{ }$ & $\sqrt{ }$ & V & 6 & - \\
\hline & & clean dish & $\sqrt{ }$ & $\sqrt{ }$ & $\sqrt{ }$ & $\sqrt{ }$ & $\sqrt{ } \sqrt{ }$ & $\sqrt{ }$ & $\sqrt{ }$ & & $\sqrt{ }$ & $\sqrt{ }$ & $\sqrt{ }$ & $\sqrt{ }$ & 6 & - \\
\hline \multirow{2}{*}{ Porsi } & Teori & $\begin{array}{l}\text { sesuai dengan } \\
\text { ukuran dan } \\
\text { takaran } \\
\text { standar resep }\end{array}$ & - & - & - & - & $-\quad-$ & - & - & & - & - & - & - & - & 6 \\
\hline & $\begin{array}{l}\text { Standar } \\
\text { Pizza } \\
\text { Marzano }\end{array}$ & $\begin{array}{l}\text { sesuai dengan } \\
\text { ukuran dan } \\
\text { takaran } \\
\text { standar resep }\end{array}$ & - & - & - & - & - & - & - & & & - & - & - & - & 6 \\
\hline \multirow{2}{*}{ Bentuk } & Teori & $\begin{array}{l}\text { potongan } \\
\text { bahan } \\
\text { makanan yang } \\
\text { bervariasi }\end{array}$ & $\sqrt{ }$ & $\sqrt{ }$ & $\sqrt{ }$ & $\sqrt{ }$ & $\sqrt{ } \sqrt{ }$ & $\sqrt{ }$ & $\sqrt{ }$ & & $\sqrt{ }$ & $\checkmark$ & $\sqrt{ }$ & $\sqrt{ }$ & 6 & - \\
\hline & $\begin{array}{l}\text { Standar } \\
\text { Pizza } \\
\text { Marzano }\end{array}$ & $\begin{array}{l}\text { Ukuran } \\
\text { potongan } \\
\text { pembagian } \\
\text { pizza }\end{array}$ & $\sqrt{ }$ & $\sqrt{ }$ & $\sqrt{ }$ & $\sqrt{ }$ & $\begin{array}{ll}\sqrt{ } & \sqrt{ }\end{array}$ & $\sqrt{ }$ & $\sqrt{ }$ & & $\sqrt{ }$ & $\sqrt{ }$ & $\sqrt{ }$ & $\sqrt{ }$ & 6 & - \\
\hline \multirow{2}{*}{ Temperatur } & Teori & $\begin{array}{l}\text { kesesuaian } \\
\text { temperatur } \\
\text { penyajian asin } \\
\text { dan manis }\end{array}$ & $\sqrt{ }$ & $\bar{V}$ & $\sqrt{ }$ & $\sqrt{ }$ & $\sqrt{ } \sqrt{ }$ & $\sqrt{ }$ & $\sqrt{ }$ & & $\sqrt{ }$ & $\sqrt{ }$ & $\sqrt{ }$ & $\sqrt{ }$ & 6 & - \\
\hline & $\begin{array}{l}\text { Standar } \\
\text { Pizza } \\
\text { Marzano }\end{array}$ & $\begin{array}{l}\text { temperatur } \\
\text { penyajian tidak } \\
\text { kurang dari } \\
65^{\circ} \text { Celcius }\end{array}$ & $\sqrt{ }$ & $\sqrt{ }$ & $\sqrt{ }$ & $\sqrt{ }$ & $\sqrt{ } \sqrt{ }$ & $\sqrt{ }$ & $\sqrt{ }$ & & $\sqrt{ }$ & $\sqrt{ }$ & $\sqrt{ }$ & V & 6 & - \\
\hline \multirow[t]{2}{*}{ Tekstur } & Teori & $\begin{array}{l}\text { kesesuaian } \\
\text { tekstur } \\
\text { makanan } \\
\text { (halus/tidak, } \\
\text { cair/padat, } \\
\text { keras/lembut, } \\
\text { kering/ } \\
\text { lembab) }\end{array}$ & $\sqrt{ }$ & $\sqrt{ }$ & - & - & $\begin{array}{ll}\sqrt{ } & \sqrt{ }\end{array}$ & $\sqrt{ }$ & $\sqrt{ }$ & & . & - & - & & 3 & 3 \\
\hline & $\begin{array}{l}\text { Standar } \\
\text { Pizza } \\
\text { Marzano }\end{array}$ & crispy (garing) & $\sqrt{ }$ & $\sqrt{ }$ & - & - & $\sqrt{ } \sqrt{ }$ & $\sqrt{ }$ & $\sqrt{ }$ & & . & - & - & & 3 & 3 \\
\hline
\end{tabular}




\begin{tabular}{|c|c|c|c|c|c|c|c|c|c|c|c|c|}
\hline \multirow{2}{*}{\multicolumn{2}{|c|}{ Dimensi }} & \multirow[t]{2}{*}{ Indikator } & \multirow{2}{*}{$\begin{array}{ll}\mathrm{H} & \mathrm{A} \\
\mathrm{C} & \mathrm{H} \\
& \mathrm{C} \\
\text { Ryan } \\
\end{array}$} & \multirow{2}{*}{\multicolumn{2}{|c|}{$\begin{array}{l}\mathrm{HC} \quad \mathrm{AHC} \\
\text { Hernandar }\end{array}$}} & \multirow{2}{*}{$\begin{array}{rr}\mathrm{H} & \mathrm{A} \\
\mathrm{C} & \mathrm{H} \\
& \mathrm{C} \\
\text { Derri } \\
\end{array}$} & \multirow{2}{*}{$\begin{array}{rr}\mathrm{H} & \mathrm{A} \\
\mathrm{C} & \mathrm{H} \\
& \mathrm{C} \\
\text { Andi } & \end{array}$} & \multirow{2}{*}{\multicolumn{2}{|c|}{\begin{tabular}{rr}
$\mathrm{HC} \quad \mathrm{A}$ \\
$\mathrm{H}$ \\
$\mathrm{C}$ \\
\multicolumn{2}{|l}{ Fahri } \\
\end{tabular}}} & \multirow{2}{*}{$\begin{array}{cc}\mathrm{H} & \mathrm{A} \\
\mathrm{C} & \mathrm{H} \\
\mathrm{C} \\
\mathrm{Aji}\end{array}$} & \multicolumn{2}{|c|}{ Hasil } \\
\hline & & & & & & & & & & & $S$ & TS \\
\hline \multirow[t]{2}{*}{ Aroma } & Teori & $\begin{array}{l}\text { hidangan } \\
\text { tersaji harus } \\
\text { sedap/harum } \\
\text { aromanya } \\
\text { sehingga } \\
\text { menimbulkan } \\
\text { selera makan, } \\
\text { aroma muncul } \\
\text { selama } \\
\text { proses } \\
\text { memasak }\end{array}$ & $\sqrt{ } \sqrt{ }$ & $\sqrt{ }$ & $\sqrt{ }$ & $\sqrt{ } \sqrt{ }$ & $\sqrt{ } \sqrt{ }$ & - & - & $\sqrt{ } v$ & 5 & 1 \\
\hline & $\begin{array}{l}\text { Standar } \\
\text { Pizza } \\
\text { Marzano }\end{array}$ & $\begin{array}{l}\text { aroma yang } \\
\text { baik }\end{array}$ & $\sqrt{ } \quad \sqrt{ }$ & $\sqrt{ }$ & $\sqrt{ }$ & $\sqrt{ } \quad \sqrt{ }$ & $\sqrt{ } \sqrt{ }$ & - & & $\sqrt{ } v$ & 5 & 1 \\
\hline \multirow{2}{*}{$\begin{array}{l}\text { Tingkat } \\
\text { Kematangan }\end{array}$} & Teori & $\begin{array}{l}\text { tingkat } \\
\text { kematangan } \\
\text { mempengaruhi } \\
\text { tekstur dan } \\
\text { bentuk warna } \\
\text { makanan } \\
\end{array}$ & $\sqrt{ } \quad \sqrt{ }$ & $\sqrt{ }$ & $\sqrt{ }$ & $\sqrt{ } \sqrt{ }$ & $\sqrt{ } \sqrt{ }$ & $\sqrt{ }$ & $\sqrt{ }$ & $\sqrt{ } v$ & 6 & - \\
\hline & $\begin{array}{l}\text { Standar } \\
\text { Pizza } \\
\text { Marzano }\end{array}$ & $\begin{array}{l}\text { tingkat } \\
\text { kematangan } \\
\text { dalam suhu } \\
357^{0} \text { celcius } \\
\text { dalam waktu } 5 \\
\text { menit }\end{array}$ & $\sqrt{ } \quad \sqrt{ }$ & $\sqrt{ }$ & $\sqrt{ }$ & $\sqrt{ } \sqrt{ }$ & $\sqrt{ } \quad \sqrt{ }$ & $\sqrt{ }$ & $\sqrt{ }$ & $\sqrt{ } v$ & 6 & - \\
\hline \multirow[t]{2}{*}{ Rasa } & Teori & $\begin{array}{l}\text { kesesuaian } \\
\text { rasa makanan } \\
\text { dengan bahan } \\
\text { makanan yang } \\
\text { digunakan }\end{array}$ & $\sqrt{ } \quad \sqrt{ }$ & $\sqrt{ }$ & $\sqrt{ }$ & $\sqrt{ } \quad \sqrt{ }$ & $\sqrt{ } \sqrt{ }$ & & - & $\sqrt{ } v$ & 5 & 1 \\
\hline & $\begin{array}{l}\text { Standar } \\
\text { Pizza } \\
\text { Marzano }\end{array}$ & $\begin{array}{l}\text { Rasa yang } \\
\text { Baik }\end{array}$ & & & & & & & & & & \\
\hline
\end{tabular}

Sumber: data diolah peneliti (2018)

Jika mengacu pada Tabel 3 maka kualitas warna dari pizza yang dibuat oleh lima staf Pizza Marzano memiliki kualitas warna yang sama, sedangkan satu staf tidak sesuai. Kualitas warna yang sesuai terjadi karena karyawan mengetahui seluruh bahan yang digunakan, proses pengolahan benar dan menghasilkan kombinasi warna yang baik dari warna bahan makanan dan proses pengolahan yang tepat. Kualitas warna yang tidak sesuai terjadi dikarenakan topping yang terlalui sedikit sehingga membuat pizza cepat kering dan gosong dan menghasilkan tekstur yang keras, sehingga warna yang dihasilkan tidak golden brown. Untuk dimensi penampilan pizza, dua staf dapur pizza Marzano memiliki kekuranyan pada penampilan pengaturan bahan makanan dan penampilan topping yang tidak merata, karena tidak digunakannya takaran ukur baku yang telah ditetapkan. Adapun dua pizza karya dua staf dapur lainnya memliliki terlalu banyak topping sehingga terlihat sangat rata tetapi tidak sesuai dengan standar resep yang berlaku. Selanjutnya dua pizza karya dua staf 
dapur lainnya memiliki penampilan yang hampir menyamai kualitas yang baik, hanya saja tidak menggunakan takaran baku yang sesuai. Selain itu ukuran porsi yang dibuat oleh seluruh staf dapur pizza Marzano tidak sesuai karena dalam penerapannya tidak menggunakan takaran ukur baku yang ada di standar resep.

Jika dinilai dari sisi bentuk pizza yang dibuat oleh seluruh staf dapur sudah memenuhi kualitas yang diinginkan mulai dari potongan bahan makanan yang bervariasi dan ukuran pemotongan pizza yang per potongnya memiliki ukuran yang sama. Untuk temperatur makanan, seluruh staf dapur mengikuti temperatur yang sesuai. Hal ini dapat diketahui dengan menggunakan termometer makanan pada saat makanan baru dikeluarkan dari oven, hasilnya seluruh makanan memiliki temperatur lebih dari 65 derajat celcius. Jika dinilai dari sisi tekstur pizza yang buat oleh staf dapur, terdapat dua pizza yang tidak memenuhi kualitas karena terlalu banyak topping yang membuat pizza menjadi soggy atau tidak crispy/garing, dua pizza lainnya memiliki topping lebih sedikit tetapi cenderung membuat pizza menjadi crispy atau akan ada kemungkinan pizza menjadi overcook dan gosong, dan dua pizza lainnya memiliki tekstur yang crispy/garing karena distribusi topping yang merata hampir menyamai kualitas yang seharusnya.

Aroma pizza yang dibuat oleh lima staf dapur memenuhi kualitas yang diharapkan yaitu aroma yang membangkitkan selera makan yang dihasilkan oleh proses memasak bahan-bahan makanan dan topping yang digunakan yaitu aroma daging, saus tomat, dan keju yang telah masak. Namun diisayangkan, terdapat satu staf dapur menghasilkan pizza dengan aroma yang tidak sesuai, karena pizza mengalami overcook yang disebabkan terlalu sedikitnya kuantitas topping sehingga pizza menjadi cepat gosong dan menghasilkan aroma gosong.

Tingkat kematangan pada pizza dilakukan sesuai dengan standar pemanggangan pizza Marzano, prosedur menyatakan bahwa seluruh pizza akan matang dengan sempurna dalam suhu 357 derajat celcius dalam waktu lima menit. Seluruh staf dapur mengetahuinya karena seluruh pizza menggunakan prosedur yang sama. Pada akhirnya, rasa yang dihasilkan oleh lima pizza yang dibuat staf dapur memenuhi kualitas yang diharapkan. Rasa diperoleh dari bahan makanan yang melalui proses pemasakan. Sedangkan rasa pizza yang dihasilkan satu staf dapur tidak sesuai standar resep karena pizza tersebut kuantitas toppingnya sedikit dan membuat pizza menjadi overcook dan menghasilkan pizza yang gosong.

\section{KESIMPULAN}

Restoran Pizza Marzano memiliki format standar resep yang memuat informasiinformasi untuk mengolah makanan dengan konsistensi kualitas dan kuantitas yang baik. Akan tetapi masih terdapat kekurangan pada beberapa komponen seperti jumlah porsi, ukuran porsi, persiapan potongan bahan makanan, dan variasi. Kebutuhan peralatan tercantum pada gambar how to card yaitu pan pizza tetapi juga tidak lengkap, tidak terdapat alat untuk menuangkan saus tomat seperti ladle (alat untuk meratakan saus seperti sendok) dan juga alat untuk menimbang bahan-bahan yang dibutuhkan. Dalam sisi penerapan standar resep, karyawan dapur Pizza Marzano menerapkan bahan-bahan, petunjuk pembuatan, dan petunjuk penyajian, tetapi tidak melakukan penerapan takaran ukur yang baku. Karyawan dapur Pizza Marzano mengetahui jumlah porsi makanan tetapi tidak 
mengetahui ukuran porsi karena tidak menggunakan takaran ukur. Karyawan dapur juga tidak mengetahui kandungan nutrisi yang terdapat pada makanan tetapi mengtahui kandungan makanan penyebab alergi dan vegetarian. Penerapan takaran ukuran di standar resep tidak diterapkan dengan baik sehingga kualitas makanan yang dihasilkan pun tidak konsisten. Kualitas makanan berdasarkan penampilan, porsi, warna, rasa, aroma dan tekstur menjadi tidak konsisten karena karyawan dapur tidak menerapkan takaran ukur. Adapun bentuk, dan suhu tidak begitu dipengaruhi oleh takaran ukur baku standar resep yang tidak digunakan, jadi tidak terlalu berpengaruh pada kualitas makanan yang dihasilkan.

Penelitian Qin, Prybutok, dan Zhao (2010) dalam Wijaya (2017) menjabarkan bahwa kualitas makanan berdasarkan variabel penampilan, porsi, warna, rasa, aroma dan tekstur sejalan empat dimensi variabel kualitas makanan (freshness, presentation, well cooked, dan variety of food) di mana dimensi well cooked memiliki nilai tertinggi. Keadaan ini dapat digambarkan dengan keadaan di mana makanan yang akan disajikan kepada konsumen harus dalam keadaan bersih (higienis), tidak ada benda asing yang berbahaya seperti rambut, serangga, dan lain-lain dan makanan yang akan disajikan kepada konsumen harus dimasak dengan suhu tertentu hingga matang sempurna guna mematikan bakteri, tapi tidak sampai overcook (gosong).

Penelitian ini mendukung temuan penelitian Namkung dan Jang (2007) dan Wijaya (2017) yang membuktikan bahwa selain dimensi well cooked, dimensi presentation juga lebih berpengaruh jika dibandingkan dengan variabel freshness, well cooked, dan variety of food. Penelitian mereka menyatakan bahwa presentasi makanan sebagai salah satu faktor kualitas makanan berpengaruh sangat dominan terhadap kepuasan konsumen. Makanan yang disajikan dengan menarik akan mendapatkan perhatian konsumen dalam memenuhi persepsi konsumen tentang kualitas.

Penelitian ini juga mendukung penelitian Mattila (2001) dalam Ryu \& Han (2010) yang membuktikan pentingnya kualitas makanan. Mattila menyatakan bahwa tiga alasan utama konsumen dalam memilih casual dining adalah kualitas makanan, pelayanan, dan suasana. Pizza Marzano sebagai salah satu restoran casual dining harus menetapkan standar resep yang ada sehingga kualitas makanan baik dari sisi penampilan dan tingkat kematangan pada nantinya dapat menjadi indikator awal untuk keseluruhan kualitas pelayanan.

Saran untuk manajemen produksi (dapur) adalah diperlukannya perbaikan mengenai susunan atau bentuk standar resep yang baku, yang mencantumkan seluruh informasi seperti: keterangan potongan, prosedur persiapan, waktu pemasakan, jumlah porsi, jumlah alat, dan nutrisi yang terkandung pada setiap porsi. Hal ini bertujuan agar seluruh staf dapur di Pizza Marzano memiliki pengetahuan, mengerti dan memahami tahapan proses pembuatan produk makanan dengan mengacu pada standar resep yang ada. Manajer juga harus melaksanakan briefing setiap awal shift dengan tujuan agar masing-masing staf dapur mengerti pentingnya standar resep, sehingga mereka yakin akan tugasnya dalam mengolah makanan, kualitas dan kuantitas produk makanan dapat dipertahankan atau bahkan menjadi yang terbaik. Chef in charge atau atasan dapur di Pizza Marzano harus selalu mengawasi dan membimbing setiap pekerjaan staf dalam mengolah makanan, sehingga penerapan standar resep akan maksimal, bukan hanya berdasarkan pengalaman, kebiasaan, ataupun perkiraan sehingga kualitas makanan pun akan konsisten setiap hari. Manajemen juga bisa memulai melakukan pelatihan kepada staf dapur jika ada menu yang tidak dimengerti agar atasan dapur dapat memvisualkan proses penerapan standar resep yang ada sehingga 
lebih mudah dimengerti dan dipahami. Penelitian ini direkomendasikan untuk dilanjutkan untuk pengukuran kualitas makanan dari sisi konsumen agar manajemen mendapat masukan dan terus melakukan improvisasi pelayanannya.

\section{DAFTAR PUSTAKA}

Anggito, Albi dan Setiawan, Johan. 2018. Metode Penelitian Kualitatif. Jawa Barat: CV Jejak.

Caserani, Victor et all. 2007. Caserani \& Kinton"s The Theory of Catering 11th edition. United Kingdom: Hodder Education.

Kotler, Philip. dan Amstrong, Gary. 2018. Marketing Principles $17^{\text {th }}$ edition. United Kingdom: Pearson Education

Kotler, Philip dan Keller, Kevin Lane. 2013. Marketing Management $14^{\text {th }}$ Edition. United Kingdom: Pearson Education

Margaretha, Fiani dan Edwin Japrianto. 2012. Analisa Pengaruh Food Quality Dan Brand Image Terhadap Keputusan Pembelian Roti Kecik Toko Roti Ganep's Di Kota Solo. Jurnal Manajeman Pemasaran. Diakses pada 14 November 2018. (http://publication.petra.ac.id/index.php/manajemenpemasaran/article/view/72).

Marsum, A.W. 2005. Restoran dan Segala Permasalahannya, Edisi IV. Yogyakarta: ANDI.

Mufqi, Taufik Suryadi. 2016. Penerapan Standar Resep di Dakken Coffee and Steak Bandung. Bandung: STP Bandung. Diakses pada 14 November 2018. (http://stpbandung.net:8080/repository/bitstream/123456789/176/1/TA\%20Taufia\% 20Mufai\%20S-201319342-2016.pdf).

Novayanti, Dian Saputri dan Sholikin, Agus. 2016. Efektivitas Kerja Cook TerhadapTingkat Kelancaran Operasional Makanan Iga Bakar di Food and Beverage Product Pada Fave Hotel Solo Baru. Solo: STP Sahid Surakarta. Diakses pada 14 November 2018. (http://jurnal.stpss.ac.id/index.php/JPI/article/view/78).

Ryu, K., \& Han, H. (2010). Influence of the Quality of Food, Service, and Physical Environment on Customer Satisfaction in Quick-Casual Restaurants: Moderating Role of Perceived Price". Journal of Hospitality and Tourism Research Vol.34, pp. 309.

Tjiptono, Fandi. dan Chandra, Gregorius. 2012. Pemasaran Strategik. Yogyakarta: ANDI

Tri, Ayu. 2014. Menu Standar Resep. Jakarta: Academia Edu. Diakses pada 14 November 2018. (https://www.academia.edu/8758992/menu standart resep).

Wijaya, Willy. 2017. Analisa Pengaruh Kualitas Makanan Terhadap Kepuasan Konsumen di Yoshinoya Galaxy Mall Surabaya. Jurnal Hospitality dan Manajemen Jasa, Vol. 5 No. 2. 